\title{
Ansiedade e aprendizagem: um estudo com díades resolvendo problemas algébricos
}

\author{
Helga Loos \\ Universidade Federal do Paraná
}

\begin{abstract}
Resumo
Partindo de uma perspectiva construtivista e interacionista, pesquisadores têm apontado o conflito sóciocognitivo como situação que favorece o desenvolvimento cognitivo em estudantes que resolvem problemas conjuntamente. Com base no pressuposto de que elementos afetivos estão interligados aos sociais e cognitivos, o estudo teve por objetivo observar como oito duplas de estudantes de sexta e sétima séries gerenciavam, simultaneamente, a busca de solução para quatro problemas algébricos, a relação interpessoal e a ansiedade gerada pelas dificuldades eventualmente encontradas. As sessões foram videografadas e analisadas qualitativamente. Observou-se que: (1) todas as duplas manifestaram ansiedade relacionada às dificuldades da tarefa; (2) uma boa interação facilitou o gerenciamento dessa ansiedade; (3) uma má interação piorou o desempenho, sendo fonte adicional de ansiedade e desencorajando o desencadeamento de conflitos sócio-cognitivos; (4) uma boa interação e um gerenciamento adequado da ansiedade não puderam garantir um bom desempenho na tarefa quando, a pelo menos um dos participantes, faltavam os requisitos cognitivos mínimos para dominá-la.
\end{abstract}

Palavras-chave: resolução de problemas; interação entre pares; ansiedade; conflito sócio-cognitivo; desempenho

\begin{abstract}
Anxiety and learning: peer interaction in solving algebraic problems. From a constructionist and interactionist perspective, researchers have shown that the socio-cognitive conflict leads to a cognitive development by students in solving-problem tasks in small groups. Based on the paradigm that affective factors are interconnected to the social and cognitive ones, this study aimed to observe sixteen $6^{\text {th }}$ and $7^{\text {th }}$ grade students in working in pairs, how they manage simultaneously: the solution search to four given algebraic problems, the interpersonal relationship and the anxiety generated by the difficulties eventually found. The sessions were recorded in video and qualitatively analyzed. It was observed that: (1) all groups manifested anxiety related to the difficulties of the task; (2) good interactions facilitated anxiety management; (3) bad interactions worsened performance, were additional source of anxiety and inhibited the emergence of socio-cognitive conflicts; (4) good interactions and appropriate management of anxiety benefited a good performance on the task, but could not assure a good performance when at least one participant did not have the minimum cognitive prerequisites to accomplish it.
\end{abstract}

Keywords: problem solving; peer interaction; anxiety; socio-cognitive conflict; performance

$\mathrm{O}$ s processos explícitos e implícitos que ocorrem durante a atividade de resolução de problemas de natureza matemática têm sido objeto de estudo de várias abordagens na Psicologia, sendo a denominada "psicologia social genética" uma das correntes que tomaram em consideração os fatores sociais que se interrelacionam com os processos cognitivos, quando os alunos trabalham em díades ou pequenos grupos.

Movimento que surgiu na década de 1970, representado basicamente por estudiosos da Escola de Genebra, tinha por principal objetivo conduzir um amplo programa de pesquisas que avaliasse o impacto do tipo de relação estabelecida quando os alunos executam uma tarefa em conjunto sobre o desenvolvimento intelectual dos mesmos.
Perret-Clermont (1979), uma das principais representantes desta abordagem, enfatizou a importante variabilidade de competências demonstradas como função da natureza da interação social que se estabelece entre os membros de uma díade que trabalha conjuntamente em uma tarefa. PerretClermont, Perret e Bell (1989) apontaram que os sujeitos não se confrontam jamais com situações ou tarefas idênticas, mesmo que estas sejam rigidamente padronizadas ou controladas. Isso ocorre porque, em uma situação como essa, aspectos cognitivos e sociais estão presentes e em constante interação, pois a relação que se estabelece estrutura, em grande parte, a tarefa e as soluções que serão aceitas.

Esta hipótese advém de uma postura que é, ao mesmo tempo, interacionista e construtivista, devendo a Vygotsky 
(1984) a concepção de que as coordenações cognitivas entre indivíduos são a base das coordenações cognitivas individuais, ou ainda, que o ato cognitivo individual não é senão um momento de um processo mais complexo que é de natureza social.

Deve muito também a Piaget (1970), pois segundo ele, é agindo sobre o meio ambiente que o indivíduo elabora os sistemas de organização de sua ação sobre o real. Todavia, as relações dos indivíduos com o meio físico não podem ser vistas como um sistema fechado, sendo a interação social uma condição necessária para essa construção. Piaget (1965) deixa transparecer a sua preocupação com a complementaridade dos processos cognitivo e social ao questionar:

se a lógica consiste numa organização de operações, que são definitivamente ações interiorizadas e tornadas reversíveis, pode-se conceber que o indivíduo consegue atingir sozinho esta organização, ou a intervenção de fatores interindividuais é necessária para explicar o desenvolvimento que acabamos de descrever? (Piaget, 1965, p.178)

Macedo (1994) explica que a operação, forma mais desenvolvida de nossa inteligência, é interpretada por Piaget como algo simultaneamente social e individual. Uma operação só tem valor explicativo se dispuser de sua recíproca, de sua inversa, isto é, a compreensão de algo que foi feito (realidade) em oposição a algo que não foi feito, mas que poderia sê-lo (virtualidade). Tal pensamento supõe capacidade de descentração e de coordenação de pontos de vista, algo de natureza simbólica ou social.

Também La Taille (1992), ao falar sobre o lugar da interação social na concepção piagetiana, descreveu precisamente os critérios utilizados por Piaget quando este se referiu ao homem como um ser social: a qualidade da "troca intelectual" entre dois ou mais indivíduos constitui-se, para ele, o elemento primordial que caracteriza a interação social. Aquele indivíduo que consegue relacionar-se com seus semelhantes de forma equilibrada, é um verdadeiro ser social. Relações de reciprocidade caracterizariam, assim, o referido equilíbrio, devendo estas se basear, principalmente, na cooperação. As relações de cooperação pressupõem, como o nome indica, “... a coordenação das operações de dois ou mais sujeitos" (La Taille, 1992, p.19), envolvendo a discussão, a troca de pontos de vista, o controle mútuo dos argumentos, sendo o tipo de relação interindividual o que mais promove o desenvolvimento.

Para Piaget (1965), uma troca intelectual equilibrada supõe, assim: (1) um sistema comum de sinais e definições; (2) a conservação das proposições válidas obrigando quem as reconhece como tais; e (3) uma reciprocidade de pensamento entre os parceiros. Opõe-se, portanto, à coação, tipo de situação em que intervém a autoridade. Nesses casos, cabe ao sujeito coagido ouvir, aceitar e reproduzir as idéias que lhe são impostas pelo outro. Trata-se, assim, de uma interação caracterizada pelo desequilíbrio.

A interação equilibrada é, portanto, algo bidirecional, e o desenvolvimento cognitivo, quando ocorre, não pode ser atribuído nem somente à interação e nem somente à ação individual. É um processo circular, e por isso mesmo, complexo.
Tais pressupostos fundamentam a proposição de que as situações em que os indivíduos podem confrontar as suas opiniões são, normalmente, mais produtivas do que os modelos prontos. A interação social permite o acesso a pontos de vista mais elaborados, atuando assim como fonte de desenvolvimento cognitivo (Perret-Clermont \& Brossard, 1988). Para Doise e Mugny (1981), progressos no domínio da cognição entre alunos que interagem em uma tarefa de resolução de problemas são freqüentemente constatados no quadro de conflitos sócio-cognitivos. Tais conflitos são provocados pelo confronto de pelo menos duas diferentes respostas advindas de indivíduos considerados "comparáveis", sendo que esse confronto tende a originar reestruturações no pensamento individual, pois a presença de um outro ponto de vista obriga cada indivíduo a considerar versões diferentes da sua própria. Um papel fundamental exerce, nesse processo, essa diferença de perspectivas em relação à tarefa, pois a existência de enfoques diferentes em torno de uma mesma situação acaba por gerar uma necessidade de mobilizar esforços no sentido de chegar a uma conclusão, a mais elaborada possível, mesmo que não seja esta a resposta "correta".

Quando, no interior do grupo, essas controvérsias são resolvidas de forma satisfatória, efeitos positivos têm sido observados sobre a socialização, o desenvolvimento intelectual e a aprendizagem escolar, ponto também defendido por Coll e Colomina (1996). No entanto, nem todos os sujeitos se beneficiam da mesma forma dessas situações de interação social, como também apontado por esses autores. Além disso, quando as controvérsias não são gerenciadas e resolvidas adequadamente, efeitos negativos podem ocorrer.

Para Johnson e Johnson (1979), a probabilidade de que sejam produzidas controvérsias depende do nível de heterogeneidade dos participantes. Essa heterogeneidade pode se referir, por um lado, aos aspectos cognitivos, como o domínio ou o conhecimento prévio na área do problema, ou às estratégias de raciocínio utilizadas, por exemplo. Mas o progresso cognitivo só ocorre quando o indivíduo possui certos pré-requisitos cognitivos que lhe possibilitam compreender a divergência existente entre os pontos de vista que estão sendo debatidos e tirar partido dos desequilíbrios produzidos na situação de interação, como demonstraram Schubaer-Leoni e Perret-Clermont (1980).

Acioly-Régnier (1996) comprovou que, aliadas a diferentes pontos de partida cognitivos, maneiras distintas de representar um mesmo problema podem dificultar, em grande medida, a busca conjunta de solução.

Ao falar da heterogeneidade como necessária à produção de controvérsias, Johnson e Johnson (1979) referiram-se ainda aos aspectos afetivos e de personalidade dos participantes, sugerindo tratar-se de fatores que contribuem para que as controvérsias sejam satisfatoriamente resolvidas ou não.

Já para Perret-Clermont, Perret e Bell (1989), um conflito sócio-cognitivo deve ser exclusivamente social e cognitivo. O termo cognitivo é utilizado “... no sentido de que a confrontação não é concernente às identidades dos participantes, às suas motivações e nem a algum outro aspecto afetivo ou emocional da interação, somente ao entendimento da tare- 
fa" (Perret-Clermont, Perret, \& Bell, 1989, p. 6). Estes autores citam possuir evidências que sugerem que quando o conflito é sócio-emocional em sua origem (quando o sujeito rejeita o ponto de vista do seu companheiro por razões sociais ou emocionais, por exemplo), o conflito não é sócio-cognitivo por natureza sendo que, então, o progresso não ocorre.

A questão central que se pode levantar nesse momento diz respeito exatamente ao rigor com que os representantes da psicologia social genética propuseram a separação entre os aspectos afetivo-emocionais e os sócio-cognitivos na análise das atividades grupais, sendo pouco provável que se possa considerar o aspecto cognitivo e o social isolados da identidade e da motivação dos participantes.

Suponha-se uma situação ideal em que não haja qualquer razão, social ou emocional, que leve um dos participantes a rejeitar "gratuitamente" o ponto de vista de qualquer de seus colegas; ou seja, que cada aluno, se discordar de um companheiro, o faça exclusivamente do ponto de vista do encaminhamento da tarefa. Ainda assim, o simples fato de os alunos estarem envolvidos em uma atividade dessa natureza, combinado ao nível de exigência da tarefa, tende a mobilizálos, podendo eles, portanto, manifestar ansiedade. Esta ansiedade estaria sendo gerada, em princípio, pelas dificuldades que os indivíduos enfrentam para dominar a tarefa, mas que pode passar a interferir, tanto nas relações interpessoais, como nas próprias construções cognitivas. O nível de ansiedade será maior ou menor de acordo com as propensões individuais e dependerá, também, da maneira com que cada um representa para si a situação que está sendo vivenciada. A ansiedade interferirá quando os conflitos cognitivos entrarem em ação, sobretudo na maneira de gerenciar tais conflitos e de conduzir a discussão a um fechamento.

A ansiedade é um aspecto afetivo-emocional que tem sido particularmente estudado em sua relação com a cognição. Pesquisas têm demonstrado que altos níveis de ansiedade influenciam negativamente a performance dos alunos, em diversos tipos de tarefas, atuando de maneira nefasta, particularmente, sobre a percepção e a memória, bem como aumentando as reações de auto-depreciação (Benjamin, Mc Keachie, Lin, \& Holinger, 1981; Eysenck, 1983; Martins, 1993; Mueller, 1978, 1979; entre outros). A ansiedade, na medida em que consiste em um comportamento não-integrativo, atrapalha o desenvolvimento construtivo do indivíduo, pois quando alguém se encontra em um estado defensivo não está aberto para a aprendizagem, nem tampouco para a consideração de pontos de vista alheios.

Considerando-se que as sessões de resolução de problemas na escola envolvem, normalmente, conteúdos matemáticos, faz-se ainda importante levar em conta os aspectos afetivos que determinam a relação particular de cada aluno com a matemática. Nimier (1988) e Bruner (citado por Nimier, 1988) analisaram que a matemática, por suas características peculiares, predispõe os indivíduos a diversos tipos de investimento emocional. Ela pode servir, para algumas pessoas, como suporte para a ansiedade e, para outras, como instrumento de defesa contra uma ansiedade originária de alguma outra fonte.
A atitude de um aluno em relação à matemática pode tomar ainda diferentes feições, dependendo do conteúdo específico a ser estudado. No caso específico da álgebra elementar, por exemplo, que constitui uma ruptura epistemológica com a aritmética (Brousseau, 1983; Vergnaud, Cortes, \& Favre-Artigue, 1987), reforçada muitas vezes por obstáculos de origem didática, a transição aritmética-álgebra representa, para a maioria dos estudantes, um momento de dificuldade, pois requer um funcionamento intelectual novo. $\mathrm{O}$ indivíduo precisa abandonar um modo interpretativo familiar, que teve seu interesse e seu sucesso, mas que se revela falso ou inadaptado no domínio das novas situações que se lhe apresentam. Necessita considerar informações que incomodam ou confundem, ou seja, que geram desequilíbrio nas concepções já existentes, e submeter os seus conhecimentos anteriores à revisão a fim de modificá-los, complementá-los ou rejeitá-los, em função da aquisição de concepções novas. E esta desestabilização cognitiva é acompanhada de uma desestabilização afetiva.

Radke-Yarrow e Sherman (1988) salientaram a necessidade de se estudar as interações entre o conhecimento, as emoções e o comportamento social, defendendo ser possível estudar as influências específicas, diretas ou em interação, dos fatores afetivos, cognitivos e sociais sobre o comportamento em um dado momento, bem como no curso do desenvolvimento. Tal necessidade justifica-se pelo risco de se chegar a determinadas conclusões sem ter levado em conta uma parte importante do problema.

Para Campos e Barret (citados por Radke-Yarrow \& Sherman, 1988), a afetividade determina, em grande parte, a organização da percepção, da cognição e do comportamento. Também Wadsworth (1993) chama a atenção para o papel seletivo desempenhado pela afetividade: é o ato de estar atento para, ou seja, representa uma forma de seleção que determina quais eventos provocam desequilíbrio (do ponto de vista piagetiano) e resultam em desenvolvimento cognitivo. Metaforicamente falando, a afetividade decide quais idéias "vivem" e quais "morrem".

Sobre este poder de determinar os conteúdos "vivos" no ser humano, Wallon, já em 1938, ao construir sua teoria psicogenética - na qual a dimensão afetiva ocupava um lugar central -, apontava para a participação total do emocional na vida intelectual. Enfatizava que a afetividade não deixa subsistir algo que possa permanecer alheio a ela, fazendo com que o indivíduo se concentre em determinados interesses e não em outros, eliminando gradualmente tudo aquilo que não pode incorporar (Werebe \& Nadel-Brulfert, 1986).

A própria Perret-Clermont e seus colegas (Hinde, PerretClermont, \& Stevenson-Hinde, 1988) chegaram a comentar sobre o caráter de complementaridade existente entre o comportamento emocional, os componentes cognitivos e o gerenciamento das relações interpessoais, que seriam guiados, especialmente, pelo desenvolvimento da intencionalidade, isto é, da coordenação entre meios e fins.

As implicações da afetividade na cognição têm sido alvo de diversos pesquisadores (para uma revisão sobre como foi tratada a relação entre a cognição e a afetividade entre algu- 
mas das principais teorias psicológicas, bem como algumas das perspectivas contemporâneas sobre o assunto, ver Loos, 1998). A afetividade é resultado de numerosos processos intrapsíquicos e interpessoais, os quais ela, por sua vez, também regula, gerando processos circulares. Assim, propõe-se que, apesar das dificuldades de se convocar concomitantemente aspectos pertencentes a estas três instâncias - cognitiva, afetiva e social -, as atividades de resolução de problemas sejam analisadas a partir dessas três perspectivas.

O presente trabalho teve por objetivos, então, avaliar: (1) o desempenho cognitivo na atividade de resolução de problemas algébricos (os recursos matemático-algébricos utilizados pelos alunos e as principais dificuldades encontradas); (2) a qualidade da interação social estabelecida nas duplas e o desencadeamento (ou não) de situações de conflito cognitivo e/ou sócio-afetivo; e (3) a manifestação e o gerenciamento da ansiedade e sua repercussão sobre a consecução da tarefa.

\section{Método}

A resolução de quatro problemas algébricos foi proposta a oito duplas de estudantes de 12 a 16 anos, cursando $6^{\mathrm{a}}$ e $7^{\mathrm{a}}$ séries de uma escola pública federal da cidade do Recife. Esses estudantes faziam parte de uma amostra de conveniência, a qual tomou parte em uma pesquisa mais ampla ${ }^{1}$, que teve como objetivo geral explorar o papel da ansiedade na aprendizagem da matemática. A referida pesquisa foi realizada em duas fases consecutivas, denominadas observação geral e observação focada. Dos 77 alunos que participaram da primeira fase, a qual foi constituída por observações em classe (em aulas de matemática), aplicação de uma sondagem de conhecimentos matemático-algébricos e uma escala de atitudes em relação à matemática, foram selecionados 16 deles, a fim de participarem da fase seguinte. A observação focada teve por finalidade, assim, aprofundar o estudo de diversos aspectos observados na primeira fase, particularmente aqueles ligados à ansiedade e sua possível relação com a matemática escolar. Esses 16 alunos submeteram-se a diversos procedimentos, entre os quais a aplicação de testes clínicos, como o Inventário de Ansiedade Traço-Estado - IDATE (Spielberger, Gorsuch, \& Lushene, 1979) e o Teste de Zulliger (Guerra, 1977), bem como, participaram das sessões de resolução de problemas descritas aqui.

Como a probabilidade de se obter um bom aproveitamento através da interação é muito maior em duplas de trabalho heterogêneas, procurou-se constituir díades que atendessem a alguns critérios de heterogeneidade, especialmente no que diz respeito ao desempenho matemático (aspecto cognitivo) e à disposição para ansiedade (aspecto afetivo-emocional). As fases anteriores da pesquisa forneceram informações acerca de tais aspectos. $\mathrm{O}$ desempenho matemático de cada aluno foi avaliado por suas notas escolares em matemática e por seu resultado na sondagem de conhecimentos matemáticoalgébricos. A disposição para ansiedade foi uma medida obtida por meio do IDATE, instrumento que permite classificar o indivíduo em variados níveis de ansiedade de base.
Foi realizado também um "mini estudo sociométrico", visando-se captar o grau de intimidade das relações entre os alunos, bem como suas preferências de parceiros para a atividade proposta. Tal procedimento buscou atender ao aspecto social, buscando-se evitar a formação de duplas que, em sua própria natureza, favorecessem o insucesso, devido a eventuais problemas de ordem sócio-emocional entre os alunos, alheios à tarefa proposta.

O "mini estudo sociométrico" foi aplicado em dois grupos de oito alunos, correspondente a cada uma das turmas ( $6^{\mathrm{a}}$ e $7^{\mathrm{a}}$ séries). Foi solicitado que os estudantes respondessem, por escrito, às seguintes questões: (1) Com quem eu mais gosto de trabalhar? Por quê? (2) Com quem eu menos gosto de trabalhar? Por quê? (3) O que eu penso a respeito dos meus colegas? (nesta última questão, cada aluno se referia nominalmente aos sete alunos restantes do seu grupo). Firmou-se o contrato de que as informações fornecidas seriam confidenciais e deixou-se claro que, no momento de se compor as duplas seriam considerados, além da preferência demonstrada por eles, os demais critérios pré-definidos.

A seleção dos problemas utilizados nas sessões se deu de acordo com um critério principal: a apresentação de estruturas algébricas críticas na questão da ruptura, a chamada crise algébrica. Os problemas selecionados para tal atividade, com suas respectivas estruturas algébricas podem ser vistos no Apêndice.

Cada aluno recebeu uma folha de trabalho, tendo-se solicitado a cada dupla que procurasse trabalhar em parceria, discutindo o máximo possível as coisas relacionadas à tarefa e tentando tomar as decisões conjuntamente. Solicitou-se também que eles fossem explicando, o mais claramente possível, o raciocínio que estavam utilizando para resolver os problemas. Cada problema requeria uma "justificativa", por escrito, após sua realização. Os alunos foram orientados a, nessa sessão, tentar descrever o método, ou o caminho escolhido para atingir o objetivo esperado, e a razão de tal opção.

Por meio das sessões de resolução de problemas pôde-se observar de que forma os alunos resolviam a tarefa proposta, tendo que gerenciar, simultaneamente: (a) questões cognitivas relacionadas à tentativa de buscar solução para os problemas; (b) questões afetivas vinculadas às dificuldades cognitivas eventualmente encontradas (por exemplo, ansiedade); (c) questões sócio-afetivas, ligadas à relação estabelecida entre cada aluno e seu companheiro de trabalho.

Todas as sessões foram gravadas em vídeo, tendo sido a análise de tipo qualitativa. A análise videográfica foi norteada por três grandes referenciais, a saber:

1) a qualidade da interação social estabelecida entre os componentes da dupla;

2) o desempenho dos participantes na tarefa, do ponto de vista das habilidades matemáticas requeridas;

3) manifestações de caráter afetivo (principalmente ansiedade), aparentemente relacionadas às dificuldades geradas pela tarefa propriamente dita, ou relacionadas a conflitos sócio-afetivos, ou ambos.

Pretendeu-se ainda, observar a repercussão do primeiro e do terceiro aspectos sobre a consecução da tarefa. 


\section{Resultados e discussão}

\section{Sobre a composição das díades}

A partir da solicitação de que os alunos demonstrassem suas preferências de parceiros para a atividade proposta, foram observados alguns pontos importantes que se mostraram determinantes de suas escolhas:

(a) as demandas do contexto relacional: em uma situação em que seria necessário resolver problemas de matemática, ou seja, dominar uma tarefa escolar, em grupo, alguns alunos procuraram buscar uma companhia conveniente para tal circunstância. Assim, algumas escolhas basearam-se na visão que o indivíduo tem de certos colegas como bons alunos, de maneira geral, ou especificamente em matemática, recusando aqueles alunos considerados como não-estudiosos, "bagunceiros", ou que não entendem nem gostam dessa matéria. Outras escolhas foram baseadas na experiência prévia de atividades grupais escolares, em que alguns colegas prestam-se melhor a esse tipo de atividade (considerados como responsáveis, interessados, que investem no trabalho, sem sobrecarregar alguns membros do grupo), contrariamente a outros. Em ambos os casos, apareceu a preocupação em garantir um bom rendimento no trabalho que seria realizado.

(b) o grau de amizade: este item contemplava a existência de relações próximas e freqüentes, ou pobres e esporádicas, ou ainda, conflitantes, relações estas que levavam a sentimentos afetuosos ou hostis direcionados aos colegas de turma. Referiu-se também à preocupação com a possibilidade de estabelecer uma relação confiável (“J. não é falsa!", por exemplo), e manifestações de simpatia pela maneira de pensar de certos colegas, que pode conter valores ou pontos de vista próximos aos seus próprios (o "pensar parecido").

Quanto às opiniões expressas acerca dos colegas, estas foram baseadas principalmente nos seguintes parâmetros:

(a) relacionamento geral com as pessoas da classe $e$ interesse comum: conversar e "se dar bem" com muita gente ou, ao contrário, ter um círculo restrito de amizades. (b) desempenho escolar em geral: investimento na aprendizagem, bom ou mau comportamento nas aulas, responsabilidade e interesse, boas notas.

(c) características pessoais e de temperamento: ser uma pessoa alegre, simpática, sincera, meiga, compreensiva, prestativa, "chata", instável, autoritária, reservada, etc., ou ainda, ter certos hábitos ou fazer determinadas brincadeiras não bem recebidas pelos colegas.

A combinação das informações obtidas através deste "mini estudo sociométrico" com aquelas referentes à disposição para a ansiedade e ao desempenho matemático-algébrico dos alunos, permitiram que se obtivesse as díades apresentadas na Tabela 1, a qual descreve as duplas, seus componentes e sua caracterização (pelos devidos fins éticos os alunos estão denominados por nomes fictícios). Cabe lembrar ainda que a série de origem de cada aluno precisou também ser respeitada, combinando-se somente alunos provenientes de uma mesma série.

A intenção foi, não somente constituir duplas heterogêneas, mas também, diversos "tipos" de duplas, com o objetivo de observar as consequiências. Observa-se no quadro apresentado que, no caso da díade Jucymara-Taís, foram combinados opostos desempenhos matemáticos de base com opostos níveis de ansiedade. As duplas Fernando-Glória e Ian-Jeferson apresentavam opostos desempenhos matemáticos de base, porém ambos os componentes da díade, elevados níveis de ansiedade. No entanto, uma das duplas era exclusivamente masculina e a outra, mista, em termos de gênero. Já as díades Ricardo-Márcia e Douglas-Cassiana, inversamente às duplas descritas anteriormente, apresentavam opostos níveis de ansiedade, mas semelhante nível de desempenho matemático-algébrico. As duplas combinaram ainda desempenhos matemáticos medianos, tanto com desempenho considerado forte (caso das duplas Joseane-Gabriela e Adriano-Tom, sendo uma delas masculina e outra, feminina), quanto com desempenho fraco, como a díade FabianoLaercio. Os níveis de ansiedade dessas últimas duplas foram

Tabela 1

Desempenho matemático e nível de ansiedade de base de cada aluno da díade

\begin{tabular}{ccc}
\hline Díades & Desempenho matemático & Ansiedade de base \\
\hline Jucymara & Forte & Baixa \\
Tais & Fraco & Alta \\
\hline Fernando & Forte & Alta \\
Glória & Fraco & Muito alta \\
\hline Adriano & Forte & Baixa \\
Tom & Mediano & Média \\
\hline Ricardo & Fraco & Muito alta \\
Márcia & Fraco & Baixa \\
\hline Ian & Forte & Alta \\
Jeferson & Fraco & Alta \\
\hline Joseane & Mediano & Média \\
Gabriela & Forte & Alta \\
\hline Fabiano & Mediano & Média \\
Laercio & Fraco & Alta \\
\hline Douglas & Fraco & Alta \\
Cassiana & Fraco & Baixa \\
\hline
\end{tabular}


também variados, sendo interessante destacar que todos os alunos da presente amostra, representantes de um desempenho matemático mediano, apresentavam, também, nível mediano de ansiedade, enquanto que os desempenhos denominados fraco tenderam a se associar mais freqüentemente a níveis elevados de ansiedade.

\section{Análise descritiva inferencial}

A análise das sessões obedeceu aos critérios previamente definidos, ou seja, a avaliação da qualidade da interação social entre os componentes de cada dupla, a avaliação do desempenho dos participantes na tarefa, contemplando-se a eventual existência de conflitos de caráter sócio-cognitivo, e a manifestação de ansiedade. Para a descrição dos resultados obtidos, considerando-se cada um desses critérios de análise, foram criadas categorias que buscam caracterizar os diferentes padrões encontrados.

\section{Sobre a qualidade da interação}

Os variados padrões, através dos quais os alunos estabeleceram suas relações com seu companheiro, foram classificados da seguinte maneira:

(a) cooperativo: os dois alunos trabalharam juntos em todos os momentos da sessão, compartilhando, inclusive, a folha de trabalho, havendo participação equilibrada e clima amigável.

(b) cooperativo, porém com certa manutenção da individualidade: os alunos discutiam, buscando construir juntos os alicerces necessários para a resolução de cada problema, mas realizavam a tarefa separadamente, comparando-a e conferindo posteriormente os procedimentos de resolução utilizados. Um aluno procurava acompanhar o outro e auxiliar quando necessário, havendo participação equilibrada e clima amigável.

(c) liderança sem resistência: um dos alunos liderava e o outro se mostrava confortável, apoiando-se no colega e mantendo um clima amigável.

(d) liderança com resistência: um dos alunos liderava e o outro se mostrava constrangido, tentando constantemente conquistar espaço e agindo, por vezes, de forma competitiva. O clima tornava-se tenso.

(e) evitação unilateral: um dos alunos bloqueava a interação, a despeito do outro demonstrar desejo de se relacionar e da entrevistadora tentar aumentar o nível de interação. O clima tornava-se tenso.

(f) individualista: os alunos demonstravam baixa interatividade, discutindo pouco e preferindo trabalhar individualmente, apesar das tentativas da entrevistadora de aumentar o nível de interação. O clima se mantinha sóbrio.

Pôde-se observar um resultado diversificado, pois em oito duplas foram encontrados seis padrões de interação diferentes.

\section{Sobre o desempenho matemático-algébrico}

Segundo este critério, as díades apresentaram-se das formas descritas abaixo:

(a) bom desempenho: ambos os componentes da díade apresentavam um desempenho considerado bom, ou um dos alunos tinha mais domínio do contexto matemático exigido e, eventualmente, reparava as falhas do outro. Entende-se por bom desempenho, quando os alunos demonstravam uma razoável compreensão conceitual e apresentavam facilidade em mobilizar os recursos algébricos e aritméticos necessários para a resolução dos problemas propostos, o que deveria envolver: compreensão do enunciado do problema; modelização adequada; manipulação algorítmica basicamente correta; pouca ocorrência de falhas aritméticas, tendo sido detectadas e contornadas pelos próprios alunos; retomada do problema após fase operacional (dando sentido aos resultados); e justificativa adequada dos procedimentos escolhidos para a busca da solução. Junto a este tipo de dupla, houve pequena participação da entrevistadora.

(b) desempenho regular: neste caso, ambos os alunos tinham um domínio apenas razoável do contexto matemático em questão, apresentando deficiências. Os problemas 1 e 2 foram resolvidos com facilidade; no entanto, nos de maior complexidade (os problemas 3 e 4), surgiram algumas dificuldades, tais como: interpretação confusa do problema na modelização, ocasionando dificuldades para gerar a equação; na manipulação adequada da equação, especialmente no problema 3 (por se tratar de uma "equação grande", envolvendo "números grandes", o problema requer muita atenção); na compreensão do raciocínio necessário para avançar na solução do problema 4, o qual exige um entendimento de proporção. Tais duplas necessitaram da freqüente intervenção da entrevistadora para avançar na solução da tarefa, e suas justificativas foram mais pobres do que as do grupo anterior, geralmente, apenas citando os procedimentos de resolução ou descrevendo o que fora feito.

(c) desempenho fraco: verificou-se que ambos os alunos apresentavam muitas dificuldades nas habilidades requeridas pela tarefa, refletindo falhas, inclusive, de nível conceitual, como por exemplo: na interpretação e na organização dos dados do problema; na escolha dos procedimentos de resolução, utilizando, como primeira opção, o "método da tentativa": achar a resposta de maneira intuitiva ou aritmeticamente; na modelização, isto é, na geração de uma equação que representasse adequadamente os dados do problema; na manipulação algorítmica, apresentando erros, por exemplo, no lidar com a incógnita e com os valores associados a ela; alta ocorrência de erros aritméticos (nas quatro operações básicas, em regras de sinais). A justificativa baseava-se em uma simples descrição do que havia sido feito, antes de uma explicitação consciente dos porquês do método escolhido. Este tipo de dupla apresentou necessidade da intensa participação da entrevistadora, no sentido de, após tentativas frustradas da parte dos alunos, fornecer "dicas" (ou até mesmo explicações) que possibilitassem o encaminhamento para a conclusão da tarefa.

\section{Sobre a manifestação de ansiedade}

Reações de ansiedade foram verificadas em todas as duplas, em diferentes graus de intensidade. Na tentativa de associar a que estariam ligadas tais manifestações, distinguiram-se, basicamente, duas fontes: 
(1) a ansiedade aparentemente ligada às dificuldades encontradas na realização da tarefa;

(2) a ansiedade aparentemente relacionada à qualidade da relação com o parceiro de trabalho.

Pôde-se constatar que, em todas as duplas, houve maior ou menor manifestação de ansiedade decorrente das dificuldades encontradas na realização da tarefa (em especial, nos problemas 3 e 4). Tal reação mostrou-se relacionada às situações em que os alunos se encontravam em um impasse, isto é, ocasiões nas quais "não sabiam o que fazer", em que não vislumbravam um caminho que os levasse a contornar a dificuldade com a qual se deparavam. Esta ansiedade refletia sentimentos que são, entre si, interligados e possuem um caráter ameaçador, como por exemplo: impotência e frustração por não estarem conseguindo dominar algo que era, no momento, importante, e que os estava desafiando; insegurança com relação às suas próprias capacidades (principalmente no caso de alunos que já apresentavam um certo comprometimento em sua auto-confiança e auto-estima); medo das potenciais conseqüências de sua "falha" (o que é comum no caso das avaliações escolares, a nota baixa e tudo o que vem ligado a ela).

Observou-se que, à medida que as pistas iam sendo conseguidas, ou seja, que o impasse ia se desfazendo, a ansiedade dava lugar a uma espécie de excitação, culminando, ao obter sucesso no empreendimento, em outras respostas afetivas, tais como a sensação de alívio (o esvanecimento da tensão) e de alegria (bem estar por ter se libertado daquelas "ameaças" que anteriormente o afligiam).

No caso da ansiedade aparentemente relacionada à qualidade da relação com o parceiro de trabalho, observou-se que a ansiedade surgia desde os momentos iniciais da ses- são, quando um dos componentes da díade assumia determinada posição com relação ao companheiro (de evitação ou de liderança), gerando reações de desagrado e, conseqüentemente, um clima de tensão.

Em um momento posterior, principalmente com o avanço da complexidade da tarefa, observou-se também, nessas duplas, o aparecimento de reações de ansiedade ligadas às dificuldades surgidas no domínio dos problemas, que se mesclava àquela anterior.

Na Tabela 2 pode-se visualizar de que forma as díades se distribuíram segundo os critérios de análise adotados.

\section{Relação entre a configuração das díades e os padrões encontrados}

Observa-se que em três das quatro duplas que apresentaram clima amigável durante a sessão, um de seus componentes possuía baixo nível de ansiedade de base. Tendo sido cultivado um clima amigável entre os participantes dessas duplas, não se manifestou qualquer tipo de ansiedade relacionada à interação. Já a ansiedade ligada às dificuldades encontradas na tarefa apareceu nessas duplas, sendo que duas das díades apresentaram pouca ansiedade, e as outras duas, muita ansiedade. Ambas as que apresentaram pouca ansiedade, tinham pelo menos um participante com nível baixo de ansiedade de base.

Nas duas díades que mantiveram clima tenso durante a sessão de resolução de problemas (Fernando-Glória e IanJeferson), ambos os alunos tinham altos níveis de ansiedadetraço. Essas duplas, além de apresentarem um padrão de interação problemático, apresentaram ansiedade ligada às dificuldades da tarefa, ou seja, ansiedade oriunda de, pelo menos, duas fontes diferentes.

Tabela 2

Padrões de interação, desempenho matemático-algébrico e manifestação de ansiedade nas díades

\begin{tabular}{|c|c|c|c|c|c|c|c|c|c|c|c|c|c|}
\hline \multirow[t]{3}{*}{ Díades } & \multicolumn{6}{|c|}{ Padrões de interação } & \multicolumn{3}{|c|}{$\begin{array}{c}\text { Desempenho } \\
\text { matemático- } \\
\text { algébrico }\end{array}$} & \multicolumn{4}{|c|}{ Manifestação de ansiedade } \\
\hline & \multicolumn{3}{|c|}{ Clima amigável } & \multirow{2}{*}{$\begin{array}{c}\begin{array}{c}\text { Clima } \\
\text { sóbrio }\end{array} \\
\text { Individualista }\end{array}$} & \multicolumn{2}{|c|}{ Clima tenso } & \multicolumn{3}{|c|}{ Tipo de desempenho } & \multicolumn{2}{|c|}{$\begin{array}{l}\text { Gerada pela } \\
\text { tarefa }\end{array}$} & \multicolumn{2}{|c|}{$\begin{array}{c}\text { Gerada pela } \\
\text { tarefa e } \\
\text { interação }\end{array}$} \\
\hline & Cooperativo & $\begin{array}{c}\text { Cooperativo } \\
\text { /individualidade }\end{array}$ & $\begin{array}{c}\text { Liderança } \\
\text { s/resistência }\end{array}$ & & $\begin{array}{c}\text { Liderança } \\
\text { c/resistência }\end{array}$ & $\begin{array}{l}\text { Evitação } \\
\text { unilateral }\end{array}$ & Bom & Regular & Fraco & Pouca & Muita & Pouca & Muita \\
\hline $\begin{array}{l}\text { Jucymara } \\
\text { Tais } \\
\end{array}$ & & $X$ & & & & & $X$ & & & & $\mathrm{X}$ & & \\
\hline $\begin{array}{c}\text { Fernando } \\
\text { Glória }\end{array}$ & & & & & $\mathrm{X}$ & & $\mathrm{X}$ & & & & & & $X$ \\
\hline $\begin{array}{c}\text { Adriano } \\
\text { Tom }\end{array}$ & & & $X$ & & & & $X$ & & & $X$ & & & \\
\hline $\begin{array}{l}\text { Ricardo } \\
\text { Márcia }\end{array}$ & $\mathrm{X}$ & & & & & & & & $\mathrm{X}$ & $\mathrm{X}$ & & & \\
\hline $\begin{array}{c}\text { Ian } \\
\text { Jeferson }\end{array}$ & & & & & & $X$ & & $\mathrm{X}$ & & & & & $\mathrm{X}$ \\
\hline $\begin{array}{l}\text { Joseane } \\
\text { Gabriela }\end{array}$ & & $\mathrm{X}$ & & & & & $\mathrm{X}$ & & & & $\mathrm{X}$ & & \\
\hline $\begin{array}{l}\text { Fabiano } \\
\text { Laercio }\end{array}$ & & & & $X$ & & & & $X$ & & $X$ & & & \\
\hline $\begin{array}{l}\text { Douglas } \\
\text { Cassiana }\end{array}$ & & & & $X$ & & & & & $X$ & & $X$ & & \\
\hline
\end{tabular}


As díades mais heterogêneas do ponto de vista de sua ansiedade de base não se apresentaram conflituosas em termos de interação, conseguindo manter um clima agradável de trabalho. O fato de um dos membros não possuir tanta propensão a reagir aos eventos com ansiedade foi, provavelmente, um fator importante para o equilíbrio emocional da dupla.

No tocante ao desempenho matemático-algébrico apresentado nas sessões, constatou-se que quase todas as duplas em que um dos membros era considerado forte atingiram um desempenho caracterizado como bom desempenho. Verificou-se, ainda, que alunos que se enquadravam individualmente em um nível fraco ou mediano mostraram progresso em interação com o seu companheiro de nível mais elevado do ponto de vista matemático. Várias situações de conflito sócio-cognitivo ocorreram, nas quais diferentes pontos de vista foram confrontados, situação esta que conduz à reestruturação do pensamento individual.

Já ambas as díades compostas exclusivamente por alunos classificados como fracos em seu desempenho individual, não demonstraram visível progresso, apresentando um desempenho conjunto também de tipo fraco. Este dado corrobora os pressupostos da teoria social genética no que diz respeito à heterogeneidade cognitiva, como pré-requisito para um bom aproveitamento através da interação. Um exemplo constitui-se a díade Ricardo-Márcia, que, embora tenha interagido de forma realmente cooperativa, apresentou um desempenho global considerado fraco.

\section{A díade Ian-Jeferson}

Ian-Jeferson foi uma das díades que apresentaram ansiedade ligada às dificuldades de interação, além daquelas relacionadas à tarefa, propriamente dita. Verificou-se que o clima de tensão foi sendo gerado a partir do posicionamento evitativo que Ian assumiu em relação a Jeferson, desde o início, independentemente das exigências da tarefa. Tal comportamento foi, provavelmente, motivado por pré-concepções por parte de Ian, tanto em relação à suposta falta de capacidade de Jeferson, como em relação ao ato de "fazer matemática" que, para Ian, trata-se de algo que "não dá para fazer em conjunto não, tem que ser individual" (sic).

A ansiedade ligada à interação foi vista, principalmente, em Jeferson, que teve frustradas as suas tentativas de interagir com o colega. Mas, no decorrer do trabalho, o contexto matemático em questão despertou diversas dificuldades em ambos os alunos, deixando perceber ansiedade também no lidar com estas dificuldades. Entretanto, Ian procurou ocultar tal fato, demonstrando uma postura, até certo ponto, "orgulhosa", evitando fazer perguntas, não assumindo com facilidade os próprios erros e nem se mostrando condescendente com as falhas ou questões feitas pelo colega. Já Jeferson teve sua própria insegurança agravada pela quase impossibilidade de contar com o colega na busca de sucesso na tarefa.

\section{A díade Fernando-Glória}

Outra díade que demonstrou problemas de interação, que se somaram às dificuldades encontradas na realização da tarefa, foi a de Fernando-Glória. Glória mostrou-se um pouco dispersa e ansiosa desde o início da tarefa (esta aluna relatou, em outro momento da pesquisa, estar sentindo dificuldade de se concentrar devido a problemas extra-escolares). As investidas de Fernando, no sentido de imprimir um ritmo vigoroso ao trabalho (Fernando demonstrava maior domínio do contexto matemático em questão, liderando e agindo de forma até um pouco autoritária) pareceram deixar Glória impaciente, em parte consigo mesma, por perceber sua dificuldade em acompanhar o colega, mas também por este não lhe conceder espaço, não respeitando o ritmo dela. Glória passou a reagir com visível contrariedade. A entrevistadora, então, interveio, buscando espaço para que ela pudesse se manifestar mais. A partir deste momento, aparentemente por ter sido tolhido em sua espontaneidade (sendo forçado a diminuir o ritmo), Fernando passou a mostrar-se impaciente e ansioso, descarregando a tensão em atos como roer unhas e balançar nervosamente a perna, e gastando o tempo "livre" - enquanto a colega terminava alguma atividade - observando a sala, as rachaduras da parede, brincando diante da câmera, por exemplo. A dupla precisou de algum tempo para se adaptar à nova situação.

Após certo período de tempo (quando trabalhavam no problema 3), Fernando começou a demonstrar um pouco mais de paciência, dedicando-se, em certos momentos, a explicar o seu raciocínio à colega. Glória, então, começou a se envolver mais com a tarefa em si, parecendo menos preocupada com o desempenho de Fernando, apesar de ainda, às vezes, reclamar por ele "terminar primeiro" (Glória agiu, durante toda a sessão, de forma competitiva).

As reações ansiosas mais ligadas à tarefa em si surgiram, com mais força, durante o problema 4, tanto em Glória como em Fernando (este problema desencadeou ansiedade em todas as duplas). No entanto, em Fernando, após a compreensão do problema e de sua solução, a ansiedade se dissipou. Já a aluna Glória, que não chegou a "digerir" muito bem o processamento do problema, apesar das explicações do colega e da entrevistadora, terminou a sessão aborrecida e desanimada.

\section{Considerações finais}

As díades Ian-Jeferson e Fernando-Glória ilustram situações em que a ansiedade manifestada parecia estar relacionada a duas fontes principais: a qualidade da interação e as dificuldades inerentes à tarefa, as quais se sobrepuseram. A díade Ian-Jeferson representa um exemplo típico de uma situação na qual a concepção negativa prévia de um dos alunos sobre o outro interferiu de forma nefasta na interação e na consecução da tarefa, uma possibilidade sugerida por PerretClermont, Perret e Bell (1989). A outra díade, porém, demonstrou dificuldades geradas na própria situação de interação. Nesse caso, o estilo de trabalho dos participantes, sendo bastante diferente, precisou ser gradativamente ajustado de forma a permitir que os alunos se beneficiassem do trabalho conjunto.

Situações como essas ilustram o quanto pode ser extremamente difícil, na prática, se entender as controvérsias, mesmo as que aparentam ser somente cognitivas, desvinculadas 
de aspectos relacionados à identidade dos participantes e às suas motivações, como também de outros aspectos afetivos ou emocionais da interação. Para Johnson e Johnson (1979), estes fatores contribuem para que as controvérsias sejam satisfatoriamente resolvidas, ou não. Poderia ser acrescentado, com base no presente trabalho, que os fatores afetivos estão indissociavelmente relacionados aos sociais e que estes não só contribuem para determinar se a resolução das controvérsias será satisfatória, como também possuem um importante papel no encaminhamento que será dado ao trabalho e na determinação do tipo de controvérsias que surgirão. Esta constatação encontra apoio nas proposições de Wallon (1938, conforme Werebe \& Nadel-Brulfert, 1986) e de Wadsworth (1993), autores que salientam o papel seletivo desempenhado pela afetividade, tanto nas relações interpessoais como nas construções cognitivas.

Entre as díades analisadas, a que encontrou a maneira mais eficaz de liberar a ansiedade que surgia, sem deixar criar uma tensão excessiva, foi a dupla Ricardo-Márcia. Apesar de ambos os alunos terem mostrado sérias dificuldades no domínio do conteúdo matemático requisitado pela tarefa, e de Ricardo apresentar ansiedade de base muito alta, a familiaridade e a boa interação estabelecida entre eles permitiu que a ansiedade gerada no contexto da tarefa fosse, aos poucos, sendo canalizada (através, por exemplo, de brincadeiras, gritinhos, "xingamentos amigáveis").

Por outro lado, para que progressos no domínio da cognição ocorram, faz-se necessário que o indivíduo possua certos pré-requisitos cognitivos que lhe permitam tirar partido dos desequilíbrios produzidos em uma situação de interação, como argumentaram Schubauer-Leoni e Perret-Clermont (1980). A dupla Ricardo-Márcia é um bom exemplo desse tipo de situação, na qual faltaram esses pré-requisitos mínimos, e assim, até o ponto em que se pôde perceber, nenhum dos componentes da díade conseguiu se beneficiar cognitivamente.

Com base nesses pressupostos teóricos, seria possível conjecturar que, se a díade em questão fosse mais heterogênea quanto ao desempenho matemático individual e mantivesse um padrão de interação tão positivo, certamente teria havido um grande progresso cognitivo. Contudo, seria possível obter-se um padrão de interação tão bom, se os níveis de desempenho individual fossem diferentes? A consciência desta diferença tenderia a originar posturas também diferenciadas? Afinal, foi o que aconteceu nas demais duplas: em nenhuma das díades, que eram diferentes do ponto de vista do desempenho individual, verificou-se um padrão interativo caracteristicamente cooperativo. Far-se-iam necessários novos estudos para melhor verificar este ponto.

Sobre a tendência do desempenho matemático das duplas ser bom quando um dos componentes era forte, constituiu-se exceção o caso Ian-Jeferson - uma das duplas em que foram observados problemas de interação e alta ansiedade, pois Ian mostrou performance mais pobre do que a detectada individualmente.

Assim, com base nas informações de que se dispõe acerca das relações entre padrões de interação, desempenho e ansiedade, por meio da análise destas sessões de resolução de problemas algébricos, pôde-se concluir que a má qualidade da interação pode piorar o desempenho, por elevar o nível de ansiedade e por desencorajar o desencadeamento de conflitos sócio-cognitivos. No entanto, a boa qualidade da interação, apesar de contribuir para o bom gerenciamento da eventual ansiedade, não garante um bom desempenho na sessão, se o "desempenho de base" de todos os componentes do grupo for problemático.

Observou-se, em todos os casos, a manifestação de ansiedade gerada pelas dificuldades encontradas na tarefa, mas esta foi mais facilmente gerenciada nos casos em que não houve um comprometimento sério na qualidade da interação.

O tipo de relação estabelecida entre os participantes da dupla em interação, em combinação com a predisposição para a ansiedade de cada um deles, determinou o clima afetivo que envolveu o trabalho, e esse clima desempenhou um papel importante na estruturação da tarefa e no encaminhamento das soluções, desde que pelo menos um dos participantes tivesse requisitos cognitivos mínimos para dominar a tarefa proposta.

Outros aspectos interessantes foram também detectados como, por exemplo, as freqüentes dificuldades na explicitação dos procedimentos utilizados na resolução dos problemas. Nesse sentido, a justificativa apresentada ao fim de cada problema pareceu exercer um papel importante na organização do pensamento, pois permitiu que os alunos retomassem o que foi feito, em um esforço do tipo metacognitivo.

Observou-se uma tendência geral (com exceção da dupla Ricardo-Márcia) de assumir uma postura de trabalho individual. Esta parece ser uma característica inerente à atividade matemática, pois, entre as demais disciplinas, parece ser mais fácil se conceber um trabalho realmente em equipe. Ian mostrou-se como o protótipo deste tipo de representação, assumindo uma posição extrema. Entretanto, foi possível detectar tal concepção implícita, em graus menores, também em outros alunos.

A proposição da tarefa baseada em dois protocolos também foi um fator que pode ter facilitado a individualização. Talvez uma postura de trabalho diferente fosse obtida se a atividade tivesse sido proposta em apenas uma folha de trabalho, comum à dupla.

Os métodos utilizados no sistema escolar parecem ser também, em parte, responsáveis pela falta de hábito apresentada pelos alunos de trabalharem em uma tarefa de forma realmente cooperativa, principalmente em matemática. Do ponto de vista piagetiano, um ser socializado é aquele que sabe agir cooperativamente (expressar ação co-operativa), isto é, manter relações de reciprocidade. Assim, pode-se questionar até que ponto a escola tem cumprido eficazmente o seu papel formativo, contribuindo para que os indivíduos de tornem, de fato, seres socializados, considerando-se o pleno alcance do termo.

\section{Referências}

Acioly-Régnier, N. M. (1996). Diz-me com quem resolves um problema de matemática e dir-te-ei quem és. In M. G. B. B. Dias \& A. G. Spinillo (Orgs.), Tópicos em Psicologia Cognitiva. Recife: Editora da Universidade Federal de Pernambuco. 
Benjamin, M., Mc Keachie, W. J., Lin, Y.-J., \& Holinger, D. P. (1981). Test anxiety: deficits in information processing. Journal of Educational Psychology, $73,816-824$.

Brousseau, G. (1983). Les obstacles épistemologiques et les problèmes en mathématiques. Recherches en Didactique des Mathématiques, 4(2), 165198.

Coll, C., \& Colomina, R. (1996). Interação entre alunos e aprendizagem escolar. In C. Coll, J. Palacios, \& A. Marchesi (Orgs.), Desenvolvimento psicológico e educação (vol. 2, pp. 298-314). Porto Alegre: Artes Médicas.

Doise, W., \& Mugny, G. (1981). Le développement social de l'intelligence. Paris: Inter Editions.

Eysenck, M. W. (1983). Anxiety and individual diferences. In G. R. J. Hockey (Org.), Stress and fatigue in human performance (pp. 273-298). Chichester: Wiley.

Guerra, A. (1977). O teste de Zulliger - uma experiência brasileira. Rio de Janeiro: CEPA.

Hinde, R. A., Perret-Clermont, A.-N., \& Stevenson-Hinde, J. (1988). Relations interpersonnelles et développement des savoirs (Symposium de la Fondation Fyssen). Genève: Del Val.

Johnson, D. W., \& Johnson, R. (1979). Conflict in the classroom: controversy and learning. Review of Educational Research, 49, 52-70.

La Taille, Y. (1992). O lugar da interação social na concepção de Jean Piaget. In Y. La Taille, M. K. Oliveira, \& H. Dantas (Orgs.), Piaget, Vygotsky, Wallon: teorias psicogenéticas em discussão (pp. 11-21). São Paulo: Summus.

Loos, H. (1998). Estudo exploratório acerca do papel da ansiedade na aprendizagem da matemática, quando da introdução à álgebra elementar. Dissertação de Mestrado não-publicada, Universidade Federal de Pernambuco, Recife.

Macedo, L. de (1994). Ensaios construtivistas. São Paulo: Casa do Psicólogo.

Martins, D. (1993). Les facteurs affectifs dans la compréhension et la mémorisation des textes. Paris: Presses Universitaires de France.

Mueller, J. H. (1978). The effects of individual differences in test anxiety and type of orienting task on levels of organization in free recall. Journal of Research in Personality, 12, 100-116.
Mueller, J. H. (1979). Anxiety and encoding process in memory. Personality and Social Psychology Bulletin, 3, 254-258.

Nimier, J. (1988). Les modes de relations aux mathématiques. Paris: Meridiens Klincksieck.

Perret-Clermont, A.-N. (1979). La construction de l'intelligence dans l'interaction sociale. Berna: Peter Lang.

Perret-Clermont, A.-N., \& Brossard, A. (1988). L'intrication des processus cognitifs et sociaux dans les interactions. In R. A. Hinde, A.-N. Perret-Clermont, \& J. Stevenson-Hinde (Orgs.), Relations interpersonnelles et développement des savoirs (pp. 441-465). Genève: Del Val.

Perret-Clermont, A.-N., Perret, J.-F., \& Bell, N. (1989, fevereiro). The social construction of meaning and cognitive activity in elementary school children. Trabalho apresentado na Conference on Socially Shared Cognition, University of Pittsburgh.

Piaget, J. (1965). Estudos sociológicos. Rio de Janeiro: Forense.

Piaget. J. (1970). O nascimento da inteligência na criança. Rio de Janeiro: Zahar.

Radke-Yarrow, M., \& Sherman, T. (1988). Interaction entre processus cognitifs et émotions au cours du développement. In R. A. Hinde, A.-N. Perret-Clermont, \& J. Stevenson-Hinde (Orgs.), Relations interpersonnelles et développement des savoirs (pp. 253-275). Genève: Del Val.

Schubaer-Leoni, M.-L., \& Perret-Clermont, A.-N. (1980). Interactions sociales et représentations symboliques dans le cadre des problèmes additifs. Recherches en Didactique des Mathématiques, 1, 297-350.

Spielberger, C. D., Gorsuch, R. L., \& Lushene, R. E. (1979). Inventário de Ansiedade Traço-Estado (Tradução e adaptação de A. Biaggio). Rio de Janeiro: CEPA.

Vergnaud, G., Cortes, A., \& Favre-Artigue, P. (1987). Introduction de l'algèbre auprès de débutants faibles: problèmes épistemologiques et didactiques. Didactique et acquisition des connaissances scientifiques, Actes du Colloque de Sevres.

Vygotsky, L. S. (1984). A formação social da mente. São Paulo: Martins Fontes. Wadsworth, B. J. (1993). Inteligência e afetividade na criança. São Paulo: Pioneira.

Werebe, M. J. G., \& Nabel-Brulfert, J. (1986). Henri Wallon. São Paulo: Ática.

\section{Nota}

1 Dissertação de mestrado da autora (Loos, 1998), realizada na Pós-Graduação em Psicologia Cognitiva, Universidade Federal de Pernambuco, sob a orientação do Prof. Dr. Jorge Tarcísio da Rocha Falcão e da Profa. Dra. Nadja Acioly-Régnier, contando com o apoio financeiro do CNPq.

Helga Loos, doutora em Educação pela Universidade Estadual de Campinas (UNICAMP), é professora na Universidade Federal do Paraná. Endereço para correspondência: Rua Eugênio Flor, 790, Apto. 612 (Pilarzinho); Curitiba, PR; CEP 82130-290. Tel.: (41) 353-2989. E-mail: helgaloos@hotmail.com ou helgaloos@yahoo.com.br 


\section{Apêndice}

Problemas propostos aos estudantes na sessão de resolução de problemas, com suas respectivas estruturas algébricas

1) Num quintal há 36 animais, entre porcos e galinhas. Sabe-se que
há, ao todo, 112 pés. Quantos são os porcos e quantas são as
galinhas? $\begin{aligned} & x+y=c \\ & a x+b x=d\end{aligned}$

